American Journal of Pharmaceutical Education 2012; 76 (7) Article 121.

\title{
ADDRESSES
}

\section{The Convergence of Excellence and Relevance}

\author{
Brian L. Crabtree, PharmD \\ 2011-2012 President, American Association of Colleges of Pharmacy \\ Address at the Opening General Session of the AACP Annual Meeting, Kissimmee, FL, July 15, 2012
}

Colleagues, I stood before you 1 year ago as your president-elect to outline the leadership agenda for the next year. I stated that we need a more balanced way to reward the diversity of excellence that exists among us, especially with regard to excellence in teaching. We need to develop preceptors as integral to the quality of the education we offer, providing evidence-based standards of excellence which we can acknowledge publicly and to which preceptors can aspire. I asked for an improved balance of our advocacy portfolio in the areas of education and research scholarship. I described significant enhancements to our research and graduate education efforts. Finally, I said for all to hear in a manner as conspicuous as I could summon, pharmacy is a science-based profession.

From the perspective of an educator whose greatest thrill and fulfillment in my career has come from teaching, I have said for years that we need an academic reward system that matches what we say in our literature and public statements, a system that rewards excellence in teaching in parity with excellence in scholarship. We aspire to excellence in all areas of our mission, but our people are diverse in passion and talent. Some of us are better at one element of our mission than others, whether that is teaching or scholarship. Excellence is worthy of reward, wherever it exists.

A problem has been that our metrics for assessment of teaching excellence are less developed than for scholarship. That was among the charges that I asked Dr. Melissa $\mathrm{S}$. Medina and her team on the Academic Affairs Committee to tackle. Education is the central mission of academic pharmacy. How can we evaluate and measure excellence in teaching?

The committee contrasted scholarly teaching with the scholarship of teaching. They outlined and defined the 6 standards of scholarly teaching:

- Clear goals

- Adequate preparation

- Appropriate methods

- Significant results

- Effective presentation

- Reflective critique
They describe in their report how to collect evidence in a systematic way and document it. Among their several recommendations to the American Association of Colleges of Pharmacy (AACP) is the creation of a fellow designation-FAACP — that would recognize excellence in scholarly teachers and the scholarship of teaching and learning.

The most exciting part of the report that thrilled me right down to my college professor bones was proposed evaluation rubrics for each of the 6 standards of scholarly teaching. At last! We have at least the beginning of a system we can use to qualitatively and quantitatively assess excellence in teaching, just as we have done for scholarship. To Melissa, staff liaison Cecilia Plaza, and members of the Academic Affairs Committee, thank you!

We all agree that the quality of education that our students receive in the experiential program is just as important as any other part of the curriculum. It is the largest part of our curriculum. Much of the experiential curriculum is conducted by preceptors who are not fulltime professional educators, often volunteers. Based on a demanding and rigorous program for documenting excellence among public schoolteachers in Mississippi, called Master Teachers, I asked Dr. Betty J. Harris and her team on the Professional Affairs Committee to consider how we can create a similar development and recognition program for pharmacy preceptors.

I want standards of excellence we can all recognize and offer to our preceptors as evidence of what we and they aspire to achieve. Utilizing a variety of resources and with the invited contributions on the committee of key staff and leaders from the American Pharmacists Association, the American College of Clinical Pharmacy, and the American Society of Health-System Pharmacists, the committee has proposed a national "master preceptor" recognition program, to be administered by AACP, based on rigorous criteria assembled in a portfolio of evidence, evaluated by the leadership of the Experiential Education Section and representatives of national practice organizations. Recipients will be awarded a certificate and a travel stipend to receive the award at their AACP/NABP (National Association of Boards of Pharmacy) regional 


\section{American Journal of Pharmaceutical Education 2012; 76 (7) Article 121.}

meeting. Their names and affiliations will be publicized in various AACP communication vehicles and celebrated by schools and colleges of pharmacy. To Betty, staff liaison Lynette Bradley-Baker and members of the Professional Affairs Committee, thank you for an amazing report!

Relevance is the second part of my leadership theme. I said as loudly and clearly as I could a year ago that science is the very foundation of pharmacy education, the foundation of our daily work. The research and education performed by our basic pharmaceutical sciences members is where it all begins.

I asked my distinguished predecessors who serve on the Argus Commission, chaired by our friend, Past President Marilyn K. Speedie, PhD, to consider vital issues at the core of a scientific foundation for clinical education, how and when it is developed, how we inculcate inquisitiveness and scholarly thinking among our students, and how we nurture emerging scientists among our students. Marilyn and Past Presidents Cindy Raehl, Vic Yanchick, Jeff Baldwin, and Rod Carter, along with the staff assistance of Lucinda Maine, produced an outstanding report called, "Cultivating 'Habits of Mind' in the Scholarly Pharmacy Clinician."

The Argus Commission was joined by leaders from academic dentistry, medicine, nursing, optometry, physician assistants, public health, veterinary medicine, and health administration programs. The Commission's report recommends "habits of mind" in the prepharmacy and professional curricula. The work reflected in their report will be important and relevant to the new Center for the Advancement of Pharmaceutical Education (CAPE) Outcomes panel that is working toward a new competency framework in 2013. To Marilyn, Lucinda Maine, and my august friends and colleagues on the Argus Commission, thank you.

Excellence and relevance impact our strategies for influencing public policy. I asked my new dean, Dr. David D. Allen, to lead the Advocacy Committee in considering an improved balance of education and science scholarship in our advocacy portfolio and to recommend strategies for demonstrating the value of academic pharmacy in the communities we serve. They stated that the benefit of academic pharmacy to the health of our nation and the world is a direct result of the teaching, research, and service of its faculty. In my view, this is the fundamental reason for faculty development: the relief and prevention of human suffering caused by illness.

Among the committee's recommendations is a more explicit expression of the importance of the quality of the education we provide, balanced with the thoughts and statements of the academy. I particularly liked the recommendation for a new commitment to education scholarship at a level that eliminates the comparison of teaching-intensive and research-intensive institutions with regard to education excellence. The committee states in its report, "The ability of pharmacy education to help communities meet their identified challenges is the best demonstration of the academy's value to that community."

This statement makes me think of present and past recipients of the Lawrence C. Weaver Transformative Community Service Award. The efforts of our members reflected in that award truly demonstrate something I heard recently: education changes lives. More than that, it changes families. And more than that, it changes communities. To David, staff liaison Will Lang, and the other members of the Advocacy Committee, thank you for your important work.

Our Chief Science Officer, Dr. Vincent Lau, with the guidance of some of our most talented and distinguished researchers in the academy, chaired a Special Advisory Committee on Research and Graduate Education to refocus and re-energize the AACP research agenda and how the Association can better serve its members to identify priorities and to strengthen relationships with key funding agencies and leading scientists. This process is ongoing, of course. What I and other leaders and staff of AACP want to make crystal clear is that all members of the academy, including our pharmaceutical scientists at traditionally research-intensive institutions, can be supported and advanced by the resources and networking of AACP.

I am delighted to announce today, officially, that AACP will launch the Academic Research Fellows Program, conceptually modeled after the highly successful Academic Leadership Fellows Program. Originally proposed by the Research and Graduate Affairs Committee charged by Past President Rod Carter, we plan to attract our successful and most promising research scientists and further develop them to become effective leaders and advocates for their own research programs and their school programs. We expect to enroll the first class of Research Fellows in the first quarter of 2013, so stay tuned for much more information about this exciting development.

Every AACP president wants to leave a legacy. I am no exception. I am inspired by the remarks of many of my predecessors, even to the extent that I sometimes carry their published addresses with me when I am thinking about inspired leadership...Bob Smith: "Unleash the Greatness"; Vickie Roche: "Ignite the Passion"; Marilyn Speedie: "Leadership in a Changing World"; Cindy Raehl: "Boldly Responding to the Academy's Needs." Leadership matters and the president can lead, but one thing I have learned is that the heavy lifting is done by 


\section{American Journal of Pharmaceutical Education 2012; 76 (7) Article 121.}

the staff and the outstanding members who are appointed to the committees in all units of governance. The staff helped me to refine the charges, and the committees made them their own, made them come to life. It is they who create the legacy and deserve our profound gratitude.

The experience of leadership in AACP has been a career highlight. As I have said to my younger colleagues so many times when speaking about the value of engagement in AACP, it has made me a better faculty member, plain and simple.

Beyond the committee initiatives, the Association made many great additional strides. They are all documented in the 2012 AACP Annual Report, which is now available online. Let me shine a special light on just a few key AACP accomplishments that are noted in the Annual Report.

To promote holistic, patient-centered healthcare, $\mathrm{AACP}$ and its partners in the Interprofessional Education Collaborative - known as IPEC - hosted a faculty development institute, Building Your Foundation for Interprofessional Education. Institution-based teams of 3 to 5 professionals participated in the May program, held in Virginia. Each team represented various facets of healthcare, including pharmacy, dentistry, allopathic medicine, nursing, osteopathic medicine, and public health. With interest in interprofessional education now widespread, the May institute sold out fast. Future regional IPEC institutes are being planned.

The Josiah Macy Jr. Foundation advanced IPEC efforts in a significant way this year. The foundation awarded funding to one of the IPEC partners, the Association of American Medical Colleges, to launch a national clearinghouse on the MedEdPORTAL. It will provide competency-linked learning resources for interprofessional education and models of team-based care.

Another highlight of the year was the increased use of the Assessment and Accreditation Management System (AAMS). AACP designed AAMS in partnership with the Accreditation Council for Pharmacy Education to help pharmacy schools and colleges fulfill their assessment and accreditation goals. Since the system's release last year, 100 schools have activated their AAMS portal, and 13 pharmacy colleges and schools have submitted self-study reports to ACPE using AAMS.

One of AACP's most significant alliances, the Global Alliance for Pharmacy Education (GAPE), expanded this year. AACP and the other original partners from Africa, Asia, Canada, and Mexico welcomed organizations from Europe, Central America, and South America into GAPE. The alliance recently launched a Web site - www.gapenet.org - to provide information about pharmacy education events and resources.

In line with AACP's strengthened global outreach, we rejoined the International Pharmaceutical Federation (FIP) as an organizational member, and we celebrated the election of several AACP members into the FIP Academic Section leadership.

I am extremely pleased with the progress that our Association has made during the past year, and I feel confident that all of you will benefit from these initiatives. I want to thank all of our volunteer leaders as well as Lucinda Maine and all of the AACP staff for your extraordinary effort and energy in making so many ideas a reality. 